\title{
Ship Ticketing System Using Near Field Communication (NFC) and SMS Gateway for Batam Island Transportation
}

\author{
Dwi Ely Kurniawan ${ }^{1}$, Agus Fatulloh ${ }^{2}$, Nur Cahyono Kushardianto ${ }^{3}$ \\ $\left\{\right.$ dwialikhs@ polibatam.ac.id ${ }^{1}$, agusf@polibatam.ac.id ${ }^{2}$, anung@polibatam.ac.id ${ }^{3}$ \} \\ ${ }^{1,2}$ Department of Informatics Engineering, Politeknik Negeri Batam, Indonesia \\ ${ }^{3}$ Department of Multimedia and Network Engineering, Politeknik Negeri Batam Indonesia
}

\begin{abstract}
Most of the people in Batam Island use ship transportation to go to the interisland. When you want to use ship transportation services, customers order tickets by buying at the counter directly. Currently, transaction archiving is still using paper, it is certainly not practical in processing the data and know the number of tickets sold. This research tries to make prototype design of ship ticket selling system using NFC device. NFC devices are communication devices with RFID-based wireless connectivity technology. RFID uses magnetic field induction to allow communication between electronic devices at close range. System design will utilize e-ID card (electronic identity certificate). The design results in the form of prototype applications on the client side and server side. The client side uses a mobile device with the Android operating system in its transaction. The server side uses a web application to store and manage ticket sales transaction data. Transactions are automated using the e-ID card as payment account identification. The server will send notification SMS to the customer every successful transaction.
\end{abstract}

Keywords: ship ticket, NFC, SMS gateway.

\section{Introduction}

Batam is part of the Riau Islands region, some of which are small islands. The main transportation to visit the inter-island is by boat. Currently, the ship is the most widely used transportation by people in rural areas. One example is the Pancung Ship. The Pancung ship is a wooden vessel that uses a 14-person motorcycle engine. The Pancung ship serves the Sekupang-Padang (round-trip). Belakang Padang is one of the sub-districts in Batam City located outside of Batam Island. According to the-Persatuan Pengemudi Motor Sangkut (PPMS), ticket price for one trip Rp. 15.000, - with 25 minutes distance from port Sekupang, Batam. The average of 200 to 300 riders is sheltering in the PPMS community. Some are located in Sekupang, Telaga Pungkur, and Belakang Padang. Average of driver Pancung operates daily reaches 10-15 vessels on a regular basis, but in big days or weekends it can increase by about 10-30 vessels in operation and the number of passengers reaches 300 people.

Currently, ticket bookings are still manual. Customers book tickets by purchasing a ticket at the nearest counter or paying directly to the clerk. Proof of ticket on paper held by each customer during the trip. Transactions in ticket sales make it difficult to know the number of tickets sold. It is certainly not practical in processing and processing ticket sales data. 
Near Field Communication Technology (NFC) is a communications device with RFIDbased wireless connectivity (Radio Frequency Identification) technology that uses magnetic field induction to enable communication between electronic devices at close range. For example, phones that are integrated with NFC technology, users can easily touch their phones to other NFC devices to buy things, share business cards, and more [1] . NFC works between two adjacent devices at a distance of several centimeters, once the connection is made in seconds, information can be exchanged between two devices, either using NFC directly or via wireless technology.

Smartphone users according to data about 65.2 million users while the population of Indonesia reached 250 million people. This means almost $30 \%$ of smartphone users in Indonesia. This is a great opportunity to integrate ship ticket applications with smartphone devices. This integration is intended to facilitate the transfer of transaction ticket data sales, and automate the process of ticket validation and recording of ticket sales data more accurately.

NFC technology has been widely applied and integrated with mobile devices. There is almost no doubt that many mobile devices have been created that have been added to the NFC. More than 150 million mobile users are already equipped with NFC by 2014 [2]. Several studies have been developed and described extensively [3] as in the use of RFID on bus ticket payments [4], use of NFC on bus tickets [5], use of NFC on cellular coupons [1], mobile credit card payments for goods and services using NFC [6], NFC Smart Tourist Card with Android mobile [7], NFC home door technology[4], and so on. In this study, the use of NFC technology is applied to ship tickets with the help of an e-ID card as a transaction medium. The balance data is stored on the e-ID card. It is expected to support the main transportation needs of suitable vessels, especially in Riau Islands, namely Batam.

\section{Method}

The research method uses a spiral software development framework, model. Beginning with communication with users to explore the needs of functional and nonfunctional systems, hardware and software specifications, and system environment are involved. Planning and modeling get a complete picture of the system.

In this study, the use of NFC technology is applied to ship tickets with the help of e-ID card as a transaction medium. The balance data is stored on the e-ID card. It is expected to support the appropriate transportation needs of flagship vessels, especially in the Riau Islands. Translation of the developed technology can be seen in the following illustration of figure 1.

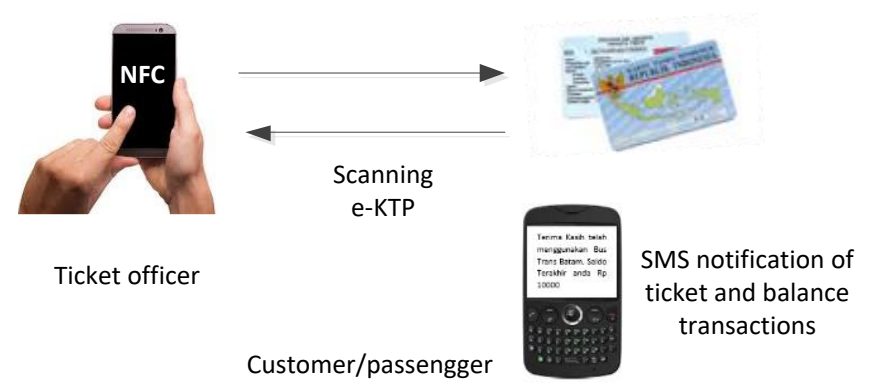

Fig. 1. The payment system uses an NFC tag of ID card with ticket confirmation via customer SMS. 
The communication phase in the software development cycle is a major phase in the excavation of technology readiness and application needs. After conducting surveys and needs in the field then compile software development documentation. Technology translation in software development after review can be seen in the following illustration of figure 2 .

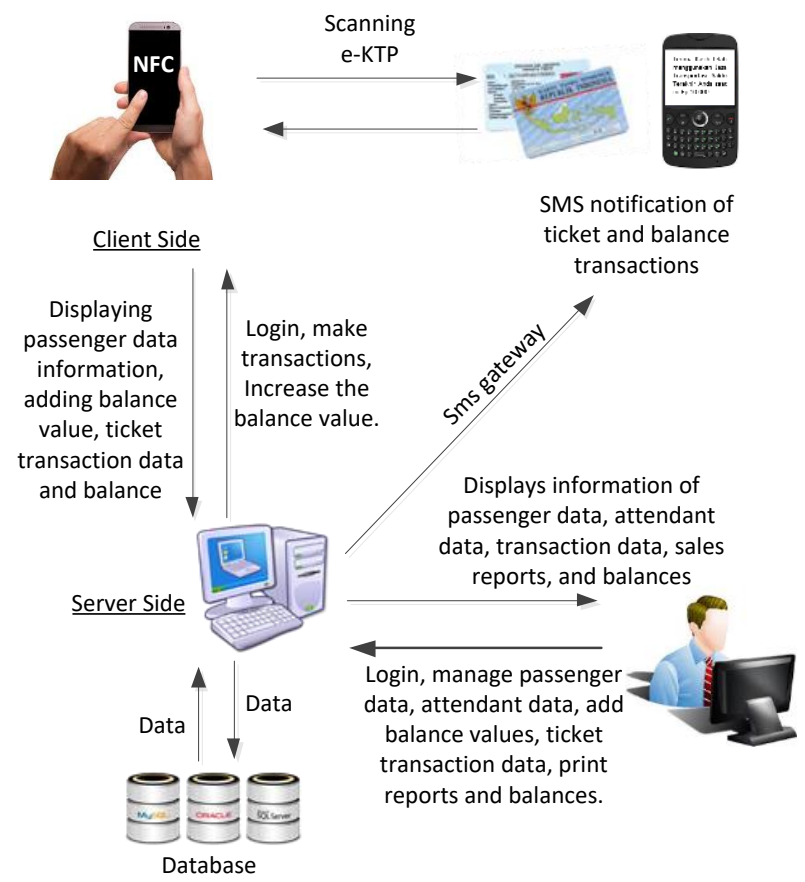

Fig. 2. Ticket sales system of Client-side and Server-side

Figure 2 show the system developed there are two sides of the client side and server side. Client-side on Android smartphone device. The client side has a functional system in performing the payment process with a scanned e-ID card of a previously registered customer. The system will verify and automate payments to customer accounts. When payment is successful then transaction result will be sent in the form of SMS notification by the gateway server. Serverside developed web-based with MySQL database. Server-side receives transaction data and processes transaction data for each customer account. The users of this app are ticket officers, counter, and admin attendant. The ticket officer is tasked with validating or automating the customer's e-ID card when going into the vessel. The cashier is assigned to serve customers in purchasing tickets, adding customer accounts, adding balance values and managing every customer transaction. The administrator has full access rights to manage ship ticket sales transaction.

Table 1. Specification of Hardware and Software Requirements

\begin{tabular}{|c|c|c|}
\hline Unit & Device & Type \\
\hline \multirow{5}{*}{ 1. PC Hardware } & Processor & Intel (R) Core (TM) Duo CPU \\
\hline & Memory & 4,00 GB RAM \\
\hline & Video Card & Intel \\
\hline & Display & 1366 x 768 (32 bit) $(60 \mathrm{~Hz})$ \\
\hline & Operating System & Ubuntu Linux \\
\hline
\end{tabular}




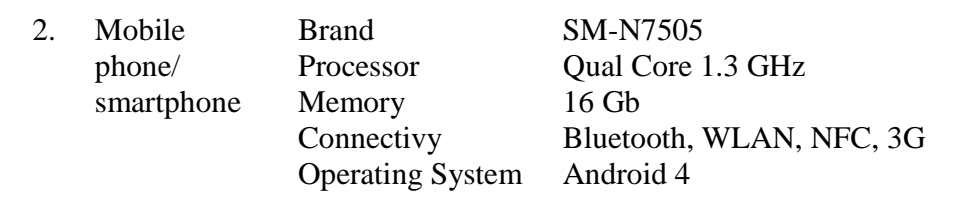

Specifications for computers and mobile devices for system development, taking into account the user environment.

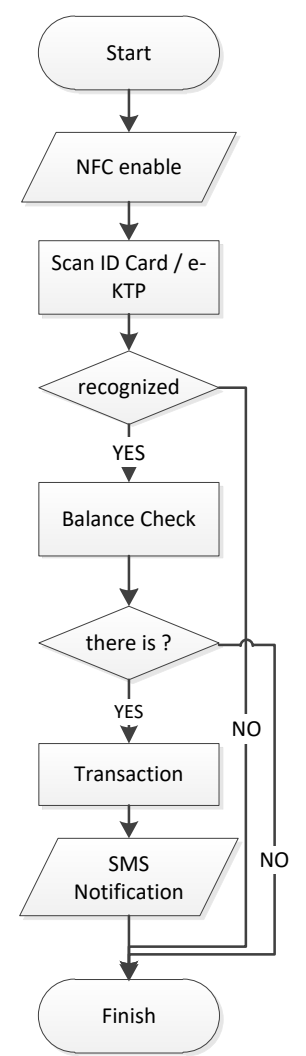

Fig. 3. Flowchart transaction ticket sales

Figure 3 show the ticket officer can enable the NFC on the smartphone device first to conduct ticket transactions. Then scan the passenger e-ID card to be able to automate the system by recognizing that passengers have been registered on the system. If not listed on the system then will not be able to make transactions with the application, so it is advisable to register and fill the balance. Unregistered customers can purchase tickets at the nearest ticketing counter. After successful e-ID scanning, the system will check the balance. If the balance is fulfilled then it can continue the transaction. But if not then customers are advised to add balance to customer's account. SMS notification will be sent by SMS Gateway server if the transaction has been successfully done. 


\section{Result}

The customer signs up to the admin/ticket attendant by providing an e-ID card as the registration material. Once the customer is registered and has a balance, the customer can already make the purchase transaction of the ship ticket. Customers can go directly and meet ticket officers by providing an e-ID card. The ticket officer performs an e-ID scan by enabling the NFC device for a ticket purchase transaction by reducing the balance and sending the proof of the transaction. If the transaction process is successful, the passenger will receive an SMS notification in the form of transaction information and current balance value.

Customer registration is done by adding customer data by doing e-ID scanning. The primary key is the ID of the e-ID card. Customer data in the form of customer name description, customer's address, customer's phone number and ship's vessel balance. Ticket officers register passengers by scanning e-ID cards.

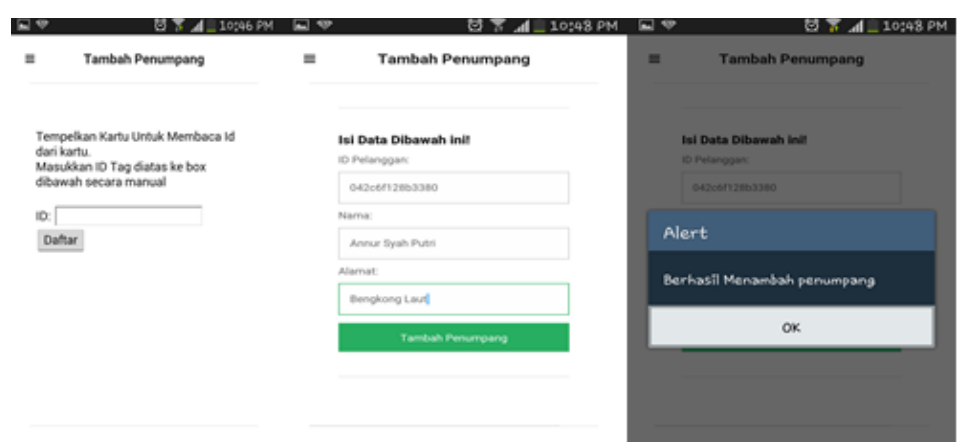

Fig. 4. Flowchart transaction ticket sales

The transaction process is done by validating the e-ID card by the ticket officer.

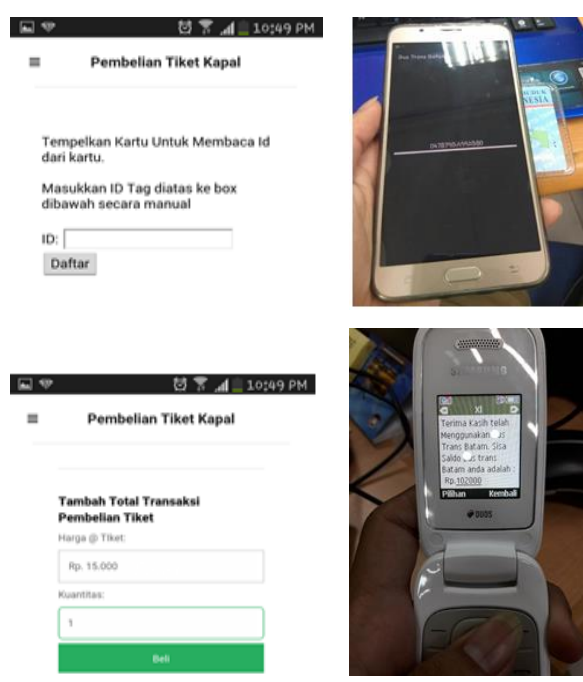

Fig. 5. Transaction system by NFC and e-KTP 
Transaction data performed on the smartphone will be sent to the web server. The server will automate by sending an SMS to the customer. SMS is generated by the system by utilizing SMS gateway. SMS received by the customer in the form of transaction result information and current balance value.

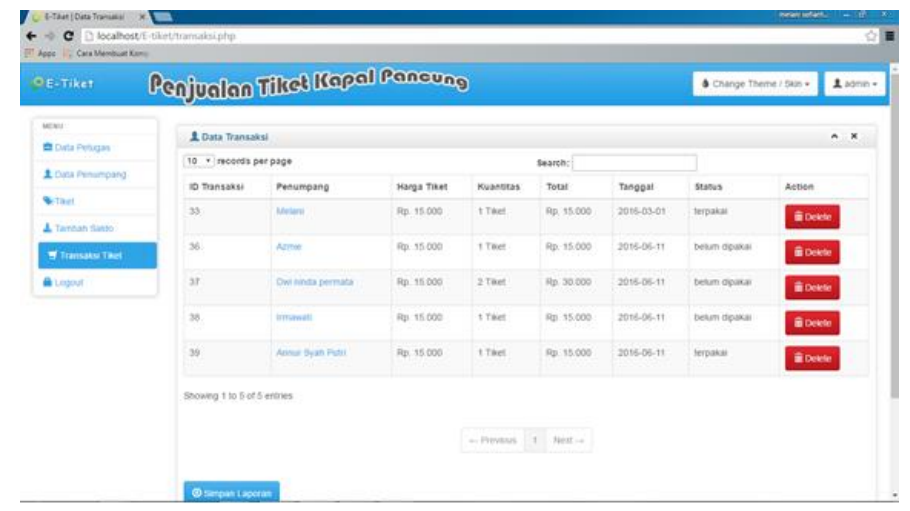

Fig. 6. Ticket transaction report in webserver

The server stores all transaction data performed by the ticket office on the smartphone device. Ticket sales transaction data is processed into financial statements for a certain period.

\section{Conclusion}

Based on the results of system development can be concluded that the system built has been able to conduct ship ticket sales transactions with NFC devices to automate each ticket purchase, making it easier for officers in making financial transaction reports for a certain period. The information of each ticket sales transaction using the SMS gateway is sent to the customer in the form of transaction result and current balance value. In addition, all transaction reports can be printed on the web server.

\section{References}

[1] H. Du, "NFC Technology: Today and Tomorrow," Int. J. Futur. Comput. Commun., vol. 2, no. 4, pp. 351-354, 2013.

[2] A. O. Pachica and J. B. L. Bernardo, "A middleware application framework for academic institution services utilizing near field communication (NFC) technology," Int. J. Appl. Eng. Res., vol. 11, no. 13, pp. 7997-8004, 2016.

[3] A. Aguiar, F. Nunes, M. Silva, and D. Elias, "Personal Navigator for a Public Transport System using RFID Ticketing,” Mobil. Transp., pp. 1-6, 2009.

[4] S. Ravi and P. Sukumar, "IoT-based Efficient Vehicle Location Help Line System using NFC,” Int. J. Emerg. Technol. Eng. Res., vol. 4, no. 5, pp. 10-13, 2016.

[5] S. Arslan, V. Demirel, and İ. Kuru, "A Public Transport Fare Collection System with Smart Phone Based NFC Interface," Int. J. Electron. Electr. Eng., vol. 4, no. 3, pp. 258-262, 2016. 
[6] C. Saminger, S. Grunberger, and J. Langer, "An NFC ticketing system with a new approach of an inverse reader mode," 2013 5th Int. Work. Near F. Commun. NFC 2013, 2013.

[7] J. . Pesonen and E. . Horster, "Near field communication technology in tourism," Tour. Manag. Perspect., vol. 4, no. 11, pp. 11-18, 2012. 